\title{
Diffusion-Weighted MR Imaging in a Prospective Cohort of Children with Cerebral Malaria Offers Insights into Pathophysiology and Prognosis
}

\author{
(D) S.M. Moghaddam, (D) G.L. Birbeck, (D)T.E. Taylor, (D).B. Seydel, DS.D. Kampondeni, and (D) M.J. Potchen
}

\begin{abstract}
BACKGROUND AND PURPOSE: Validation of diffusion-weighted images obtained on 0.35T MR imaging in Malawi has facilitated meaningful review of previously unreported findings in cerebral malaria. Malawian children with acute cerebral malaria demonstrated restricted diffusion on brain MR imaging, including an unusual pattern of restriction isolated to the subcortical white matter. We describe the patterns of diffusion restriction in cerebral malaria and further evaluate risk factors for and outcomes associated with an isolated subcortical white matter diffusion restriction.
\end{abstract}

MATERIALS AND METHODS: Between 2009 and 2014, comatose Malawian children admitted to the hospital with cerebral malaria underwent admission brain MR imaging. Imaging data were compiled via Neurolnterp, a RedCap data base. Clinical information obtained included coma score, serum studies, and coma duration. Electroencephalograms were obtained between 2009 and 2011. Outcomes captured included death, neurologic sequelae, or full recovery.

RESULTS: One hundred ninety-four/269 (72.1\%) children with cerebral malaria demonstrated at least 1 area of diffusion restriction. The most common pattern was bilateral subcortical white matter involvement (41.6\%), followed by corpus callosum (37.5\%), deep gray matter (36.8\%), cortical gray matter (17.8\%), and posterior fossa (8.9\%) involvement. Sixty-one (22.7\%) demonstrated isolated subcortical white matter diffusion restriction. These children had lower whole-blood lactate levels $(\mathrm{OR}, 0.9 ; 95 \% \mathrm{Cl}, 0.85-0.98)$, were less likely to require anticonvulsants (OR, 0.6; $95 \% \mathrm{Cl}, 0.30-0.98)$, had higher average electroencephalogram voltage (OR, 1.01; 95\% Cl, 1.00-1.02), were less likely to die (OR, 0.09; $95 \% \mathrm{Cl}, 0.01-0.67)$, and were more likely to recover without neurologic sequelae (OR, 3.7; 95\% Cl, 1.5-9.1).

CONCLUSIONS: Restricted diffusion is common in pediatric cerebral malaria. Isolated subcortical white matter diffusion restriction is a unique imaging pattern associated with less severe disease and a good prognosis for full recovery. The underlying pathophysiology may be related to selective white matter vulnerability.

ABBREVIATIONS: $C M$ = cerebral malaria; IWMDR = isolated subcortical white matter diffusion restriction; $E E G$ = electroencephalogram

$\mathbf{M}^{2}$ alaria remains a common burdensome disease with 219 million new infections and 435,000 deaths in 2017. ${ }^{1}$ Pediatric cerebral malaria (CM), the most severe form of the disease, maintains a fatality rate of $15 \%-25 \%$ with long-term neurologic disability in $35 \%-45 \%$ of survivors despite treatment with anti-

Received April 4, 2019; accepted after revision June 28.

From the Department of Imaging Sciences (S.M.M., M.J.P.), and Department of Neurology, Department of Public Health, Center for Experimental Therapeutics (G.L.B.), University of Rochester, Rochester, New York; Department of Osteopathic Medical Specialties (T.E.T., K.B.S.), Michigan State University, East Lansing, Michigan; and Queen Elizabeth Central Hospital (S.D.K.), University of Malawi College of Medicine, Blantyre, Malawi.

This work was supported by the Harry W. Fischer Research Fund, University of Rochester Medical Center Department of Imaging Sciences. Partial funding was provided by the National Institutes of Health: The CHASE Study, NIHR01NS094037.

Paper previously presented at: American Society of Neuroradiology Annual Meeting and the Foundation of the ASNR Symposium, May 18-23, 2019; Boston, Massachusetts. malarials that clear parasitemia within hours. ${ }^{2}$ Postmortem studies have shown that $\mathrm{CM}$ has diverse pathologic findings, highlighting the complex nature of the host/parasite interaction., MR imaging studies have shown a wide range of findings, ${ }^{5}$ further underscoring the complex nature of this disease. Past use of imaging has helped illuminate pathophysiologic mechanisms driving morbidity and mortality of CM, showing that brain swelling on initial MR imaging predicts death ${ }^{6}$ and demonstrating regions of focal brain atrophy on CT in survivors with epilepsy that correspond to the epileptic foci. ${ }^{7}$

Our group has previously reported the various patterns of MR imaging findings in CM and discussed their implications in terms

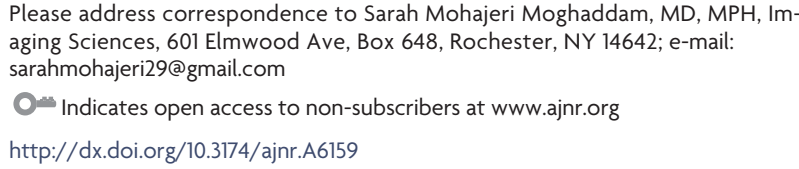

AJNR Am J Neuroradiol 40:1575-80 Sep 2019 www.ajnr.org 
of the underlying pathophysiologic processes involved in CM. ${ }^{5,6,8}$ The most commonly observed patterns of structural abnormality on CM brain MR imaging include diffuse brain swelling and distinct patterns of abnormalities on $\mathrm{T} 2$ in the basal ganglia, cerebral cortex, and white matter. ${ }^{5}$ The initial reports did not include DWI findings due to limitations of the $0.35 \mathrm{~T}$ technology in our Malawibased study site. Through additional sequence acquisition and postprocessing, we have now validated the DWI data from the Malawi MR imaging. ${ }^{9}$ Therefore, this report details the DWI findings in this large cohort of children with pediatric CM.

DWI is a mainstay of neurologic imaging and should offer important insights into diseases in resource-limited tropical settings that are only now benefiting from access to advanced imaging technology. DWI signal changes reflect edematous changes in the brain parenchyma from cytotoxic edema. One mechanism of cytotoxic edema is transsynaptic injury, which is thought to be caused by excitotoxic amines released through a number of pathophysiologic mechanisms. ${ }^{10}$ Receptors associated with excitotoxic mechanisms are distributed throughout the brain, in both gray and white matter. ${ }^{11}$ Resultant DWI changes from this mechanism occur in astrocytes, oligodendrocytes, the myelin sheath, and axons, leading to intramyelinic cytotoxic edema. Low ADC values are generally thought to represent areas of cell death. However, cytotoxic edema is a premorbid state, and in some circumstances, reversibility is possible. ${ }^{12}$ This is exemplified by recent work in stroke imaging, which has found, with great accuracy, differences in ADC values between infarcted white matter and penumbra with a reversible potential after tissue plasminogen activator administration. ${ }^{13}$

Diffusion-weighted sequences are commonly used to evaluate ischemic stroke and neoplasms. However, diffusion restriction is seen in a number of other conditions and provides insight into their pathophysiology. These conditions include hypoxic-ischemic encephalopathy, ${ }^{14}$ diffuse axonal injury, ${ }^{15}$ and toxic ${ }^{16}$ or metabolic $^{17}$ leukoencephalopathy. Diffusion restriction reversibility has been described in several conditions - most commonly involving the white matter. Examples of conditions in which there can be reversible white matter-restricted diffusion include demyelinating disease, ${ }^{18}$ heroin-induced encephalopathy, ${ }^{19}$ postictal state, ${ }^{20}$ hypoglycemia, ${ }^{21}$ and vigabatrin-associated vacuolar myelinopathy. ${ }^{22}$

Among children admitted to the pediatric research ward with $\mathrm{CM}$ in Blantyre during several years, we observed various patterns of diffusion restriction, including the unusual finding of isolated subcortical white matter diffusion restriction (IWMDR) in a substantial minority $(22.7 \%)$ of children with CM. Given the unique nature of this pattern of diffusion restriction and the limitations in our present understanding of coma etiology in children with $\mathrm{CM}$, in addition to descriptively reporting the DWI findings from the pediatric CM cohort, we further evaluated risk factors for and outcomes associated with white matter-restricted diffusion in pediatric CM.

\section{MATERIALS AND METHODS}

Children admitted to the pediatric research ward of Queen Elizabeth Central Hospital between 2009 and 2014 who met the World Health Organization definition of CM and demonstrated malarial retinopathy ${ }^{23,24}$ were eligible for inclusion in the study. When possible, initial imaging was performed within 12 hours of admission. Children who died or regained consciousness before imaging could be performed and those whose parents did not consent to enrollment in the study were excluded. Standard clinical care including emergent antimalarial treatment was provided according to ward protocols in all cases. ${ }^{25}$

The appropriate local and United States research ethics committees approved this work. Demographic, clinical, electroencephalogram (EEG), and imaging data were prospectively collected. Clinical variables included temperature, Blantyre coma scale score ${ }^{6}$ at admission, platelet count, whole-blood lactate level, white blood cell and glucose levels, systolic blood pressure, HIV status, seizures before admission, histidine-rich protein levels-a marker of parasite burden, ${ }^{26}$ the presence/absence of clinical seizures, and overall coma duration. Coma duration was imputed for those who died to be 2 SDs above the mean coma duration in the survivors. Outcomes captured included death, neurologic sequelae at discharge, or intact survival. Admission EEGs were obtained between 2009 and 2011. ${ }^{6}$ EEG characteristics included average and maximal voltage, dominant rhythm frequency, sleep architecture, variability, reactivity, presence and location of slowing, and presence of asymmetry.

Two fellowship-trained radiologists, one trained in MR imaging with 13 years of experience and the other trained in neuroradiology with 16 years of experience, blinded to patient outcomes interpreted all MR imaging. Data were compiled into a searchable RedCap data base developed for this project called "NeuroInterp." ${ }^{27}$ Among imaging data collected were the presence or absence of DWI findings in various anatomic locations. DWI sequences were acquired via standard protocol, previously validated on this $0.35 \mathrm{~T}$ Signa Ovation Excite MR imaging scanner (GE Healthcare, Milwaukee, Wisconsin). ${ }^{9}$ Abnormal findings on DWI were described as being present versus absent; if findings were present, we indicated the predominant location involved, including involvement of the subcortical white matter, cortical gray matter, globus pallidus, putamen, caudate, corpus callosum, and/or posterior fossa. The radiologists provided independent interpretations with discrepancies addressed by consensus review.

A case definition of IWMDR was developed using NeuroInterp-derived data. Cases included those that demonstrated subcortical diffusion restriction, excluding those with concurrent basal ganglia and cortical diffusion restriction. ${ }^{28}$ Of note, occasional abnormal findings on DWI were also seen in the corpus callosum and posterior fossa in this subgroup.

Statistical analysis was conducted using Epi Info, Version 7.2 (https://www.cdc.gov/epiinfo/index.html). Statistical associations for categoric clinical, and outcome variables were determined using Pearson $\chi^{2}$ tests. Statistical differences in continuous variables were determined using Student $t$ and ANOVA tests. Univariate logistic regression models were used to estimate relevant correlation coefficients, which are reported as odds ratios. A $P$ value $<.05$ was considered significant.

\section{RESULTS}

A total of 269 consecutive pediatric patients with $\mathrm{CM}$ meeting the inclusion criteria were imaged on the 0.35T Signa Ovation Excite 


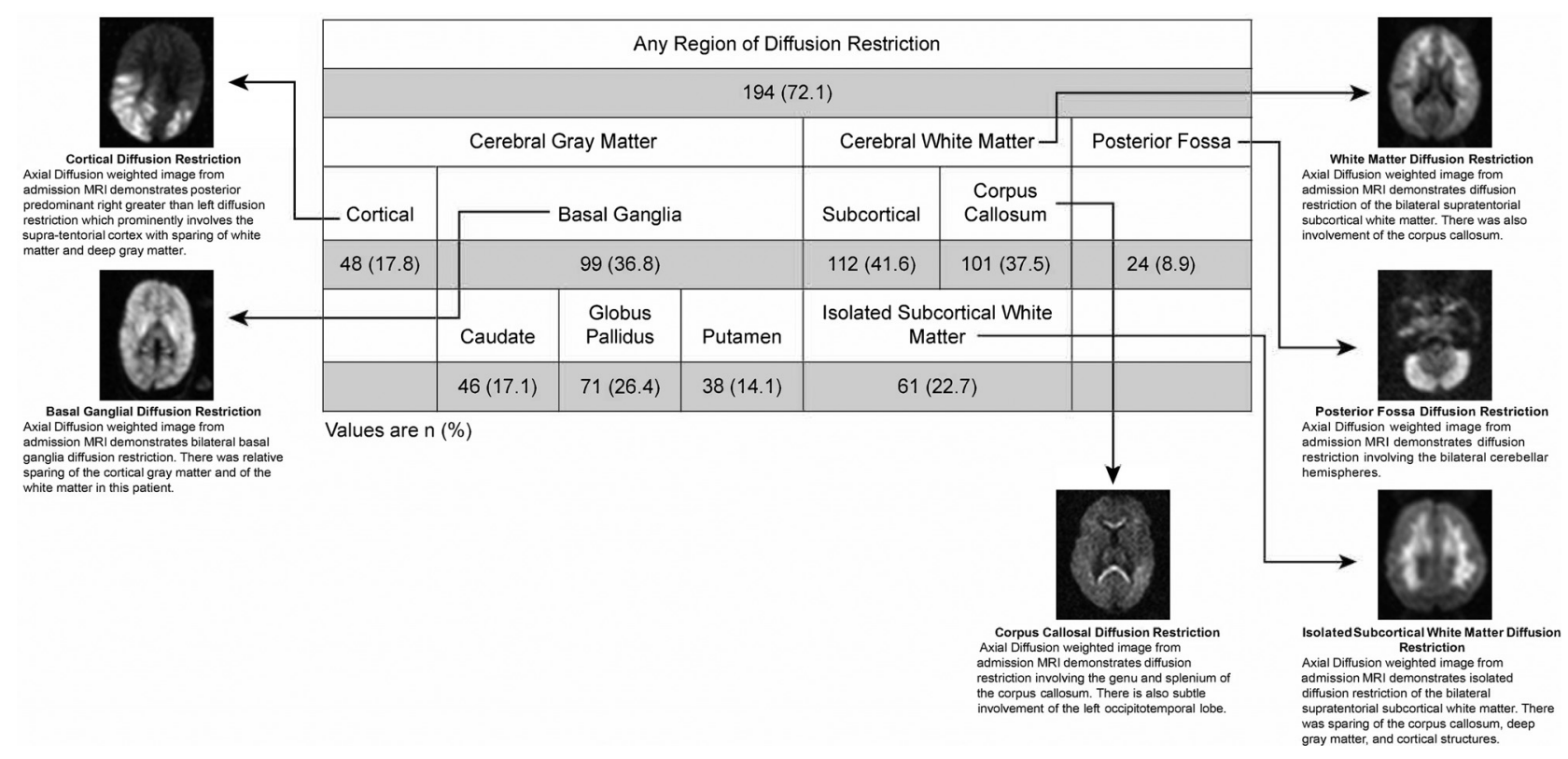

FIG 1. Patterns of diffusion restriction on admission MR imaging in children with retinopathy-positive cerebral malaria. Numbers in each category are reported as No. (\%). Examples of each observed pattern are illustrated with accompanying description.

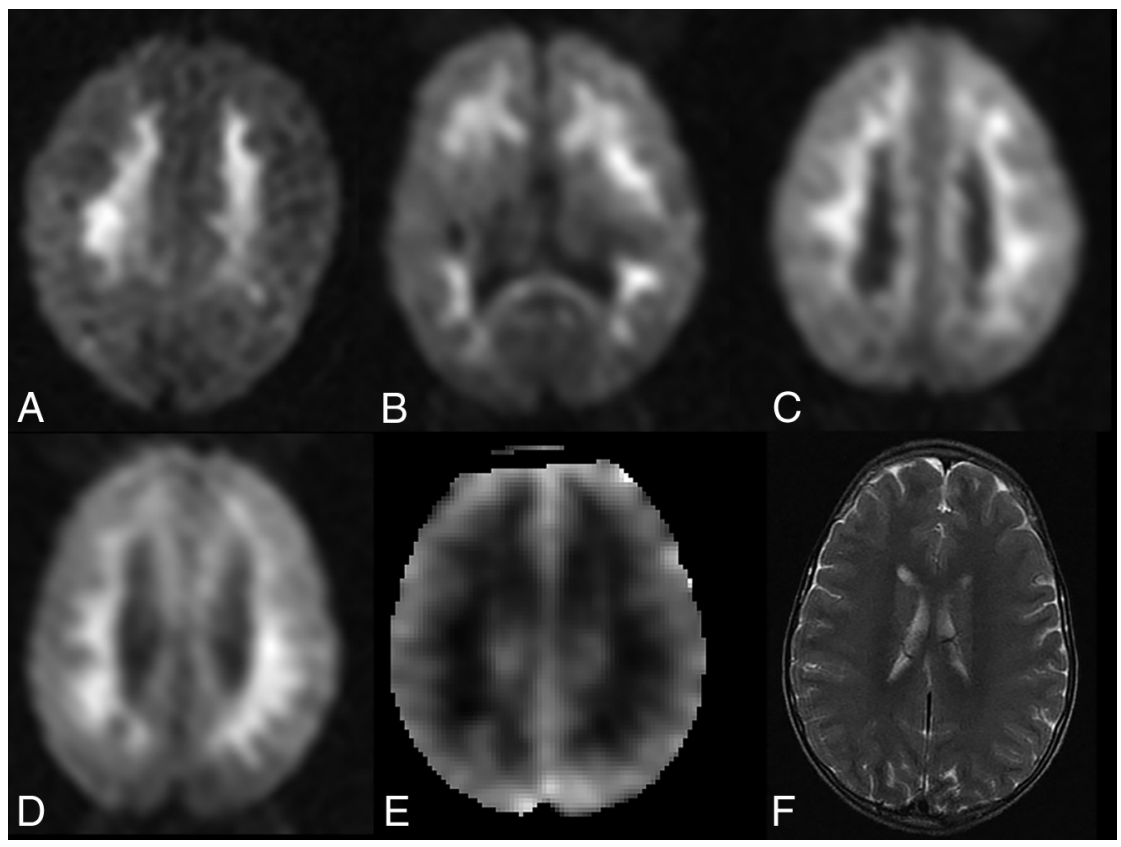

FIG 2. IWMDR on initial brain MR imaging in children with cerebral malaria. A-C, Axial diffusionweighted images in 3 different comatose children with acute cerebral malaria. There are confluent regions of diffusion restriction in the subcortical white matter without involvement of the cortex or deep gray matter. $D-F$, Axial DWI in a different patient demonstrates a similar pattern of white matter hyperintensity on diffusion-weighted images, with corresponding hypointensity on ADC maps, consistent with true diffusion restriction. Axial T2-weighted image demonstrates subtle regions of corresponding $\mathrm{T} 2$ hyperintensity.

MR imaging scanner between 2009 and 2014. The mean age was 51.4 months. One hundred ninety-four/269 (72.1\%) demonstrated at least 1 area of diffusion restriction. Patterns of gray matter involvement included the cortex in 48/269 (17.8\%) and the basal ganglia in $99 / 269$ (36.8\%) children. Basal ganglia involvement was most commonly seen in the globus pallidus (71/ $269,26.4 \%)$. White matter involvement was predominantly bilateral and subcortical $(112 / 269,41.6 \%)$ and/or corpus callosal (101/
269, 37.5\%). Diffusion restriction was less commonly observed in the posterior fossa $(24 / 269,8.9 \%)$ (Fig 1).

Sixty-one (22.7\%) children with CM demonstrated the unusual pattern of IWMDR (Fig 2). IWMDR occurred exclusively in the subcortical regions with no periventricular involvement. Children with IWMDR had significantly lower whole-blood lactate levels (mean, 5.4 versus $6.9 \mathrm{mmol} / \mathrm{L}$; OR, 0.9; 95\% CI 0.85-0.98). They were also less likely to require anticonvulsant medication on admission and have clinical seizures (57\% versus 71\%; OR, 0.6; 95\% CI, $0.30-0.98)$. There was no significant difference between the groups in terms of admission temperature and Blantyre coma scale score, platelet count, white blood cell count, serum glucose levels, systolic blood pressure, HIV status, seizures before admission, and histidinerich protein levels.

A total of 155/269 children had admission EEGs, of which 36 (23\%) demonstrated IWMDR. The average EEG voltage was significantly higher in the IWMDR group (128.9 versus $104.5 \mu \mathrm{V}$; OR, 1.01; 95\% CI, $1.00-$ $1.02)$. Higher average voltage was associated with survival in prior studies on Malawian children with $\mathrm{CM}^{6,29}$ and in a pooled Malawian and Ugandan CM population. ${ }^{29}$

Although additional EEG variables did not reach statistical significance, likely due to the small sample size ${ }^{30}$ with IWMDR, there were additional EEG trends within this group that previously conferred favorable outcomes. ${ }^{29}$ These include a higher 
Table 1: Clinical characteristics and outcomes associated with IWMDR in children with cerebral malaria ${ }^{a}$

\begin{tabular}{|c|c|c|c|c|c|}
\hline & IWMDR+ & IWMDR- & OR & $95 \% \mathrm{Cl}$ & $P$ Value \\
\hline \multicolumn{6}{|l|}{ Clinical characteristics } \\
\hline Admission temperature $\left({ }^{\circ} \mathrm{C}\right)$ & $38.9 \pm 1.1$ & $38.8 \pm 1.2$ & 1.11 & $0.87-1.42$ & .40 \\
\hline Plasma lactic acid levels (mmol/L) & $5.4 \pm 3.6$ & $6.9 \pm 4.5$ & 0.91 & $0.85-0.98$ & .02 \\
\hline Systolic blood pressure (mm Hg) & $41.2 \pm 214.7$ & $74.9 \pm 137.6$ & 1.00 & $0.99-1.00$ & .14 \\
\hline HIV status & $5(9.6 \%)$ & $32(16.3 \%)$ & 0.55 & $0.20-1.48$ & .23 \\
\hline Reported preadmission seizure & $53(89.8 \%)$ & $171(83.0 \%)$ & 1.80 & $0.72-4.52$ & .21 \\
\hline Plasma glucose level (mmol/L) & $6.4 \pm 2.1$ & $6.7 \pm 3.6$ & 0.97 & $0.89-1.06$ & .49 \\
\hline Plasma HRP-II levels & $10.2 \pm 10.2$ & $10.8 \pm 10.1$ & 0.99 & $0.96-1.02$ & .67 \\
\hline Received anticonvulsant at admission & $35(57.4 \%)$ & $148(71.2 \%)$ & 0.55 & $0.30-0.98$ & .04 \\
\hline Admission Blantyre coma scale score & $1.4 \pm 0.6$ & $1.3 \pm 0.6$ & 1.44 & $0.90-2.31$ & .13 \\
\hline Admission white blood cell count $\times 10^{-9 / L}$ & $10.5 \pm 7.9$ & $11.3 \pm 7.9$ & 0.98 & $0.95-1.03$ & .51 \\
\hline Platelet count $\times 10^{-9 / L}$ & $56 \pm 60$ & $59 \pm 64$ & 1.00 & $1.00-1.00$ & .81 \\
\hline \multicolumn{6}{|l|}{ EEG characteristics } \\
\hline Average voltage $(\mu \mathrm{V})$ & $128.9 \pm 50.7$ & $104.5 \pm 53.5$ & 1.01 & $1.00-1.02$ & .02 \\
\hline Maximum voltage $(\mu \mathrm{V})$ & $251.1 \pm 75.8$ & $219.4 \pm 88.5$ & 1.00 & $0.99-1.01$ & .06 \\
\hline Sleep architecture & $20(55.6 \%)$ & $66(55.5 \%)$ & 1.00 & $0.47-2.13$ & .99 \\
\hline Dominant rhythm frequency $(\mathrm{Hz})$ & $2.3 \pm 0.9$ & $2.4 \pm 1.7$ & NA & NA & .56 \\
\hline Variability & $24(66.7 \%)$ & $69(58.0 \%)$ & 1.45 & $0.66-3.17$ & .35 \\
\hline Reactivity & $20(58.8 \%)$ & $45(40.5 \%)$ & 2.10 & $0.96-4.58$ & .06 \\
\hline General slowing & $35(97.2 \%)$ & $105(90.5 \%)$ & 3.67 & $0.46-29.4$ & .22 \\
\hline Paradoxic reactivity & $10(50 \%)$ & $17(37.0 \%)$ & 1.70 & $0.59-4.93$ & .32 \\
\hline Asymmetry & $7(19.4 \%)$ & $34(28.8 \%)$ & 0.60 & $0.24-1.49$ & .27 \\
\hline \multicolumn{6}{|l|}{ Outcomes } \\
\hline Overall coma duration (hrs) & $47.5 \pm 25.3$ & $74.8 \pm 43.9$ & 0.98 & $0.97-0.99$ & $<.001$ \\
\hline Full recovery & $55(90.2 \%)$ & $148(71.2 \%)$ & 3.70 & $1.50-9.10$ & .004 \\
\hline Survival with sequelae & $5(8.2 \%)$ & $27(13.0 \%)$ & 0.60 & $0.22-1.63$ & .32 \\
\hline Death & $1(1.6 \%)$ & $33(15.9 \%)$ & 0.09 & $0.01-0.67$ & .02 \\
\hline
\end{tabular}

Note:-HRP-II indicates histidine-rich protein, a marker of parasite burden; IWMDR + , subjects with purely subcortical white matter abnormalities, excluding those with cortical DWI abnormalities and those with basal ganglia DWI abnormalities; IWMDR-, those who did not meet criteria for IWMDR+; NA, not applicable.

a Values are No. (\%) or means.

maximum EEG voltage (251.1 versus $219.4 \mu \mathrm{V}$ ) and more likelihood of demonstrating retained reactivity $(58.8 \%$ versus $40.5 \%)$ and nonfocal slowing (97.2\% versus $90.5 \%$ ). There were no differences in dominant rhythm frequency, presence of sleep architecture, variability, or asymmetry.

In terms of outcomes, IWMDR was associated with a shorter period of coma and improved outcome at discharge. Only one (1.6\%) of those with IWMDR died versus 33 (15.9\%) of those without the finding (OR, 0.09; 95\% CI, 0.01-0.67). Of those who survived, 55 (90\%) fully recovered without evidence of neurologic sequelae at discharge (90\% versus 71\%; OR, 3.7; 95\% CI 1.5-9.1) (Table 1).

\section{DISCUSSION}

In the largest series of pediatric cases of CM imaged to date, restricted diffusion was frequently seen, and the finding of isolated restricted diffusion of the subcortical white matter, an MR imaging finding not often seen with other conditions, was remarkably common and was associated with less severe disease clinically and better outcomes. White matter diffusion restriction was associated with lower lactate levels and a lower odds of clinical seizure-2 established predictors of disease severity supporting these patients having a less severe disease state. ${ }^{31}$ The preceding finding may underscore the concept of "selective vulnerability," wherein white matter-restricted diffusion changes can be seen without cortical or deep gray matter involvement because the white matter is more susceptible to various transient deleterious physiologic changes. ${ }^{14}$ In cases of CM coma with good outcome, isolated white matter dysfunction related to selective and revers- ible white matter vulnerability may explain the previously inexplicable nature of this rapidly reversible coma.

Although uncommon in other settings, isolated white matter transient restricted diffusion has been described in several other disease states (Table 2). Acute toxic leukoencephalopathy, which occurs as a result of various drug or environmental exposures, shows symmetric areas of $\mathrm{T} 2$ hyperintensity in the periventricular white matter, often with associated diffusion restriction, and the findings are frequently reversible if toxic exposure is removed and follow-up imaging is performed. ${ }^{16,32}$ Acute toxic leukoencephalopathy-associated isolated white matter-restricted diffusion is thought to arise from intramyelinic cytotoxic edema and resultant myelin vacuolization, capillary endothelial injury inducing cytotoxicity, and/or direct toxic demyelination. ${ }^{16}$ Endothelial injury is a central pathophysiologic mechanism in CM. A substantial number of children in our cohort $(61 / 269,22.7 \%)$ demonstrated diffuse subcortical white matter involvement, similar to the typical appearance of acute toxic leukoencephalopathy though with a distribution in the subcortical regions. A recent large-scale study of Malawian children with CM found extensive alterations in blood metabolites during CM compared with levels during convalescence, ${ }^{33}$ implicating circulating metabolites possibly playing some role in the overall pathogenesis.

Reversible diffusion restriction is also described in acute severe hypoglycemia, in which restricted diffusion most commonly involves the internal capsule, centrum semiovale, and cerebral cortex and is commonly reversible with appropriate timely treatment. ${ }^{21,30,34,35}$ In hypoglycemia, the pathophysiology of diffusion 
Table 2: Conditions with reversible/transient white matter diffusion restriction and their pathophysiology

\begin{tabular}{|c|c|c|}
\hline Condition & Proposed Pathophysiology & Relevance to Cerebral Malaria \\
\hline $\begin{array}{l}\text { Acute toxic } \\
\text { leukoencephalopathy }\end{array}$ & $\begin{array}{l}\text { Intramyelinic edema, myelin vacuolization } \\
\text { Capillary endothelial injury } \\
\text { Direct toxic demyelination }{ }^{16}\end{array}$ & Endothelial injury is a pathophysiologic mechanism in $\mathrm{CM}^{38}$ \\
\hline Hypoglycemia & Energy failure leading to excitatory edema ${ }^{21}$ & $\begin{array}{l}\text { Hypoglycemia is a frequent complication in } \\
\text { children with severe falciform malaria }{ }^{39} \text {; } \\
\text { local/focal hypoglycemia may occur due to } \\
\text { sludging even in the absence of } \\
\text { systemic hypoglycemia }\end{array}$ \\
\hline Peri-/postictal state & $\begin{array}{l}\text { Increased metabolic demand leading to energy } \\
\text { failure and resultant cytotoxic and } \\
\text { vasogenic edema }{ }^{40}\end{array}$ & $\begin{array}{l}\text { Seizures, often recurrent, are a frequent manifestation of CM } \\
\text { and associated with worse outcome }{ }^{29}\end{array}$ \\
\hline $\begin{array}{l}\text { Penumbra of ischemic } \\
\text { infarct }\end{array}$ & $\begin{array}{l}\text { Early white matter ischemic injury with axonal } \\
\text { swelling and intramyelinic edema }{ }^{13}\end{array}$ & $\begin{array}{l}\text { Sequestration in postcapillary venules of the brain } \\
\text { and venous congestion are central to } \\
\text { CM pathogenesis }\end{array}$ \\
\hline Demyelination & $\begin{array}{l}\text { Immune-mediated perivenular } \\
\text { inflammation and demyelination }{ }^{41}\end{array}$ & $\begin{array}{l}\text { Vascular inflammatory markers are associated with } \mathrm{CM} \text {, } \\
\text { and perivenular inflammation is thought to contribute } \\
\text { to } \mathrm{CM} \text { pathogenesis }\end{array}$ \\
\hline
\end{tabular}

restriction is not definitively understood but is thought to be related to transmembrane pump energy failure leading to cytotoxic edema and/or excitatory edema. The latter is thought to be responsible for those with predominantly white matter involvement, whose outcomes tend to be more favorable. Our study also showed this finding to be related to favorable CM outcomes with a fatality rate of $0.7 \%$ versus $12.6 \%$ in the sample overall. Although systemic hypoglycemia is rapidly addressed on admission and would not have been present at the time of imaging, focal metabolic energy failure due to vascular sludging, hyperpyrexia, seizures, and other drivers of high-energy demand ubiquitous in CM could be anticipated and could be reversible with optimal care. Glutamate levels are significantly lower during the acute phase of pediatric $\mathrm{CM},{ }^{33}$ supporting the supposition that energy failure could play a role in diffusion restriction.

Hyperthermia has been shown to increase the excitatory amino acids glutamate and aspartate as well as inhibitory amino acids gamma-aminobutyric acid and glycine in the brain. Significant reduction in cerebral blood flow, edema formation, and cell injuries is evident. ${ }^{36}$ While we did not find a direct relationship between white matter DWI changes and temperature, the temperature at the time of the MR imaging was not specifically noted and markedly elevated temperatures of $>39^{\circ} \mathrm{C}$ during the acute phase are a hallmark of this disease. Therefore, the absence of an association may be related to the temporal nature of our data collection. These changes lead to excitatory edema rather than frank cytotoxic edema. Review of postmortem specimens from prior studies on Malawian children with cerebral malaria has failed to demonstrate intramyelinic edema, ${ }^{4}$ and an excitatory edema state is more likely present, which could lead to findings of restricted diffusion. The presence of excitatory edema would also help explain another unusual finding in cerebral malaria, in which there is an acute onset of coma, which generally resolves with a short duration.

Mechanisms involved in early cytotoxic edema in infarct penumbra $^{12,13}$ are also of particular interest in CM. The current understanding of the pathophysiology of CM predominantly involves the presence of microvascular sequestration. Postmortem studies have demonstrated the presence of sequestration within the postcapillary venules of the brain. ${ }^{25}$ Cerebral white matter is highly vulnerable to the effects of focal ischemia. Pathologic changes in oligodendrocytes and myelinated axons appear early and seem to be concomitant with, but independent of, neuronal perikaryal injury. ${ }^{37}$ Microvascular occlusion may lead to venous congestion and regional hypoperfusion, with the downstream sequelae of excitatory edema in underperfused regions of the brain. This phenomenon could be transient if the patient is treated before progression to cell death occurs.

\section{CONCLUSIONS}

Isolated restricted white matter diffusion is common in pediatric $\mathrm{CM}$ and is associated with less severe disease and better outcomes compared with patients who do not demonstrate this finding. The underlying pathophysiology of this finding is not thoroughly understood and may result from the selective vulnerability of white matter to several potentially reversible deleterious pathophysiologic changes that occur in patients with CM. IWMDR may represent a marker for a better prognosis. In CM, low ADC values occur in the absence of cytotoxic edema. Other etiologies for fluid redistribution resulting in restricted water motion, such as excitatory edema, should be considered.

Disclosures: Gretchen L. Birbeck—UNRELATED: Board Membership: Fogarty International Center Advisory Board and the American Neurological Association; Consultancy: GlaxoSmithKline, Comments: related to neuropsychiatric effects of antimalarial drugs; Grants/Grants Pending: National Institutes of Health. Karl B. SeydelUNRELATED: Employment: Blantyre Malaria Project. Michael J. Potchen—RELATED: Grant: National Institutes of Health*; UNRELATED: Expert Testimony: expert witness in medical legal cases; Grants/Grants Pending: National Institutes of Health and Radiological Society of North America.* Terrie E. Taylor-RELATED: Grant: National Institutes of Health*; UNRELATED: Board Membership: Novartis Institute for Tropical Diseases; Employment: Michigan State University*; Grants/Grants Pending: National Institutes of Health*; Payment for Lectures Including Service on Speakers Bureaus: Novartis Institute for Tropical Diseases. *Money paid to the institution.

\section{REFERENCES}

1. World Health Organization. World malaria report 2018. License: CC BY-NC-SA 3.0 IGO. https://www.who.int/malaria/publications/ world_malaria_report/en/. Accessed April 10, 2019

2. Lopera-Mesa TM, Doumbia S, Chiang S, et al. Plasmodium falciparum clearance rates in response to artesunate in Malian children with malaria: effect of acquired immunity. J Infect Dis 2013;207: 1655-63 CrossRef Medline 
3. Milner DA Jr. Rethinking cerebral malaria pathology. Curr Opin Infect Dis 2010;23:456-63 CrossRef Medline

4. Dorovini-Zis K, Schmidt K, Huynh H, et al. The neuropathology of fatal cerebral malaria in Malawian children. Am J Pathol 2011;178: 2146-58 CrossRef Medline

5. Potchen MJ, Kampondeni SD, Seydel KB, et al. Acute brain MRI findings in 120 Malawian children with cerebral malaria: new insights into an ancient disease. AJNR Am J Neuroradiol 2012;33: 1740-46 CrossRef Medline

6. Seydel KB, Kampondeni SD, Valim C, et al. Brain swelling and death in children with cerebral malaria. $N$ Engl J Med 2015;372:1126-37 CrossRef Medline

7. Kampondeni SD, Potchen MJ, Beare NA, et al. MRI findings in a cohort of brain injured survivors of pediatric cerebral malaria. Am J Trop Med Hyg 2013;88:542-46 CrossRef Medline

8. Postels DG, Li C, Birbeck GL, et al. Brain MRI of children with retinopathy-negative cerebral malaria. Am J Trop Med Hyg 2014;91: 943-49 CrossRef Medline

9. Zhuang Y, Potchen MJ, Kampondeni SD, et al. Validation of diffusion measurements obtained on a 0.35T MR in Malawi: important insights for radiologists in low income settings with low field MRI. Magn Reson Imaging 2018;45:120-28 CrossRef Medline

10. Moritani T, Smoker WR, Sato Y, et al. Diffusion-weighted imaging of acute excitotoxic brain injury. AJNR Am J Neuroradiol 2005;26: 216-28 Medline

11. Hassel B, Boldingh KA, Narvesen C, et al. Glutamate transport, glutamine synthetase and phosphate-activated glutaminase in rat CNS white matter: a quantitative study. J Neurochem 2003;87:230-37 CrossRef Medline

12. Liang D, Bhatta S, Gerzanich V, et al. Cytotoxic edema: mechanisms of pathological cell swelling. Neurosurg Focus 2007;22:E2 Medline

13. Sato A, Shimizu Y, Koyama J, et al. A new threshold of apparent diffusion coefficient values in white matter after successful tissue plasminogen activator treatment for acute brain ischemia. J Neuroradiol 2017;44:223-26 CrossRef Medline

14. Chalela JA, Wolf RL, Maldjian JA, et al. MRI identification of early white matter injury in anoxic-ischemic encephalopathy. Neurology 2001;56:481-85 CrossRef Medline

15. Zheng WB, Liu GR, Li LP, et al. Prediction of recovery from a posttraumatic coma state by diffusion-weighted imaging (DWI) in patients with diffuse axonal injury. Neuroradiology 2007;49:271-79 CrossRef Medline

16. McKinney AM, Kieffer SA, Paylor RT, et al. Acute toxic leukoencephalopathy: potential for reversibility clinically and on MRI with diffusion-weighted and FLAIR imaging. AJR Am J Roentgenol 2009;193:192-206 CrossRef Medline

17. Maheen Anwar SS, Mubarak F, Sajjad Z, et al. 5-FU induced acute toxic leukoencephalopathy: early recognition and reversibility on DWI-MRI. J Coll Physicians Surg Pak 2014;24(Suppl 1):S8-10

18. Koelman DL, Benkeser DC, Klein JP, et al. Acute disseminated encephalomyelitis: prognostic value of early follow-up brain MRI. J Neurol 2017;264:1754-62 CrossRef Medline

19. Barnett MH, Miller LA, Reddel SW, et al. Reversible delayed leukoencephalopathy following intravenous heroin overdose. J Clin $\mathrm{Neu}$ rosci 2001;8:165-67 CrossRef Medline

20. Cianfoni A, Caulo M, Cerase A, et al. Seizure-induced brain lesions: a wide spectrum of variably reversible MRI abnormalities. Eur J Radiol 2013;82:1964-72 CrossRef Medline

21. Kang EG, Jeon SJ, Choi SS, et al. Diffusion MR imaging of hypoglycemic encephalopathy. AJNR Am J Neuroradiol 2010;31:559-64 CrossRef Medline

22. Pearl PL, Vezina LG, Saneto RP, et al. Cerebral MRI abnormalities associated with vigabatrin therapy. Epilepsia 2009;50:184-94 CrossRef Medline

23. Newton CR, Chokwe T, Schellenberg JA, et al. Coma scales for children with severe falciparum malaria. Trans $\mathrm{R}$ Soc Trop Med Hyg 1997;91:161-65 CrossRef Medline

24. Molyneux ME, Taylor TE, Wirima JJ, et al. Clinical features and prognostic indicators in paediatric cerebral malaria: a study of 131 comatose Malawian children. Q J Med 1989;71:441-59 Medline

25. Taylor TE, Molyneux ME. The pathogenesis of pediatric cerebral malaria: eye exams, autopsies, and neuroimaging. Ann N Y Acad Sci 2015;1342:44-52 CrossRef Medline

26. Dondorp AM, Desakorn V, Pongtavornpinyo W, et al. Estimation of the total parasite biomass in acute falciparum malaria from plasma PfHRP2. PLoS Med 2005;2:e204 CrossRef Medline

27. Potchen MJ, Kampondeni SD, Ibrahim K, et al. NeuroInterp: a method for facilitating neuroimaging research on cerebral malaria. Neurology 2013;81:585-88 CrossRef Medline

28. Helenius J, Soinne L, Perkiö J, et al. Diffusion-weighted MR imaging in normal human brains in various age groups. AJNR Am J Neuroradiol 2002;23:194-99 Medline

29. Postels DG, Wu X, Li C, et al. Admission EEG findings in diverse paediatric cerebral malaria populations predict outcomes. Malar $J$ 2018;17:208 CrossRef Medline

30. Aoki T, Sato T, Hasegawa K, et al. Reversible hyperintensity lesion on diffusion-weighted MRI in hypoglycemic coma. Neurology 2004; 63:392-93 CrossRef Medline

31. Idro R, Marsh K, John CC, et al. Cerebral malaria: mechanisms of brain injury and strategies for improved neurocognitive outcome. Pediatr Res 2010;68:267-74 CrossRef Medline

32. Rimkus Cde M, Andrade CS, Leite Cda C, et al. Toxic leukoencephalopathies, including drug, medication, environmental, and radiation-induced encephalopathic syndromes. Semin Ultrasound CT MR 2014;35:97-117 CrossRef Medline

33. Gupta S, Seydel K, Miranda-Roman MA, et al. Extensive alterations of blood metabolites in pediatric cerebral malaria. PLoS One 2017; 12:e0175686 CrossRef Medline

34. Terakawa Y, Tsuyuguchi N, Nunomura K, et al. Reversible diffusionweighted imaging changes in the splenium of the corpus callosum and internal capsule associated with hypoglycemia: case report. Neurol Med Chir (Tokyo) 2007;47:486-88 CrossRef Medline

35. Schmidt P, Böttcher J, Ragoschke-Schumm A, et al. Diffusionweighted imaging of hyperacute cerebral hypoglycemia. AJNR AmJ Neuroradiol 2011;32:1321-27 CrossRef Medline

36. Sharma HS. Methods to produce brain hyperthermia. Current Protocols in Toxicology; 2005;23:11.14.1-11.14.26

37. Pantoni L, Garcia JH, Gutierrez JA. Cerebral white matter is highly vulnerable to ischemia. Stroke 1996;27:1641-46; discussion 1647 CrossRef Medline

38. Conroy AL, Phiri H, Hawkes M, et al. Endothelium-based biomarkers are associated with cerebral malaria in Malawian children: a retrospective case-control study. PLoS One 2010;5:e15291 CrossRef Medline

39. Taylor TE, Molyneux ME, Wirima JJ, et al. Blood glucose levels in Malawian children before and during the administration of intravenous quinine for severe falciparum malaria. $N$ Engl J Med 1988; 319:1040-47 CrossRef Medline

40. Xiang T, Li G, Liang Y, et al. A wide spectrum of variably periictal MRI abnormalities induced by a single or a cluster of seizures. J Neurol Sci 2014;343:167-72 CrossRef Medline

41. Love S. Demyelinating diseases. J Clin Pathol 2006;59:1151-59 CrossRef Medline 